\title{
GESTÃO DOS RECURSOS HÍDRICOS NO BRASIL COMO POLÍTICA DE DESENVOLVIMENTO: DESERTIFICAÇÃO E O ESGOTAMENTO DO AÇUDE DE COREMAS/PB
}

\author{
Igor Barbosa Beserra Gonçalves Maciel ${ }^{1}$ \\ Jailton Macena de Araújo ${ }^{2}$
}

Resumo: O presente artigo aborda a gestão dos recursos hídricos no Brasil como uma política de desenvolvimento, voltando-se para o Açude de Coremas/PB, cujo estado é crítico. Através do método de abordagem dedutivo, de procedimental explicativo e a técnica de pesquisa bibliográfica-documental, objetiva-se analisar o papel do estado no desenvolvimento econômico, a essencialidade da água para a vida dos seres vivos e para o desenvolvimento econômico, a gestão dos recursos hídricos no Brasil, o esgotamento do Açude de Coremas/Paraíba e estratégias para evitar a desertificação das regiões abastecidas por Coremas. Ao final, apresentar-se-ão as considerações finais.

Palavras-chave: Gestão. Recursos hídricos. Política de Desenvolvimento. Açude de Coremas. Esgotamento.

\section{WATER RESOURCES MANAGEMENT IN BRAZIL AS A DEVELOPMENT POLICY: DESERTIFICATION AND DEPLETION OF THE COREMAS' WEIR - PARAIBA}

\begin{abstract}
This paper approaches the management of water resources in Brazil as a development policy, turning to the Coremas' Weir/Paraiba, whose state is critical. Through the deductive approach method, the explanatory procedure and the bibliographic-documentary research technique, the objective are to analyze the role of the state in economic development, the essentiality of water for the life of living beings and for economic development, the management of water resources in Brazil, the depletion of the Coremas' weir/Paraíba and strategies to avoid desertification of the regions supplied by Coremas. Finally, the final remarks will be presented.
\end{abstract}

Keys-words: Management. Hydric resources. Development policy. Coremas' weir. Depletion.

\footnotetext{
${ }^{1}$ Mestrando em Direito Econômico pelo Programa de Pós-Graduação em Ciências Jurídicas/UFPB. Bolsista CAPES/DEMANDA SOCIAL. Advogado licenciado. Editor Assistente da Prim@ Facie (Revista do PPGCJ).

${ }^{2}$ Doutor e Mestre em Ciências Jurídicas. Professor Permanente do Programa de Pós-Graduação em Ciências Jurídicas/UFPB. Editor Gerente da Prim@ Facie (Revista do PPGCJ/UFPB).
} 
"Mas o lindo prá mim é céu cinzento

Com clarão entoando o seu refrão

Prenúncio que vem trazendo alento

Da chegada das chuvas no sertão

Ver a terra rachada amolecendo

A terra antes pobre enriquecendo

O milho pro céu apontando

O feijão pelo chão enramando"

Gonzaguinha

\section{INTRODUÇÃO}

A Constituição da República Federativa do Brasil de 1988 conferiu ao Estado inúmeros poderes e atribuições. Dentre estes, está o dever de promover o desenvolvimento em múltiplas concepções, de modo a não se restringir apenas ao aspecto econômico ou financeiro, mas para proporcionar uma grande transformação social, cultural e política.

Neste aspecto a utilização das águas, como recurso natural escasso e cujo manejo exige um esforço do Estado brasileiro para sua preservação, demandando uma atuação positiva que oriente a transformação socioeconômica, especialmente, no Nordeste do país, região mais atingida com a escassez da água.

A esta evidência, o açude de Coremas, situado no alto-sertão paraibano se coloca como instrumento de promoção do desenvolvimento, que se coaduna a esta preocupação. $\mathrm{O}$ Açude de Coremas do Estado da Paraíba - que é o maior reservatório de água do Estado da Paraíba, possui capacidade para fornecimento de água a mais de 500 mil pessoas, sendo, aproximadamente, 400 mil paraibanos e 100 mil potiguares.

Atualmente, o referido açude encontra-se com um volume de água de apenas $15,61 \%$ da sua capacidade, segundo a Agência Executiva de Gestão de Águas do Estado da Paraíba AESA, não obstante a sua dimensão. Entre as principais causas do esgotamento do açude, tem-se as fortes mudanças climáticas, como a estiagem e o aumento da temperatura da Terra, geradas ou intensificadas pela ação antrópica e ligadas às emissões de gases do efeito estufa, além do mau gerenciamento desse grande reservatório de água doce.

A essa evidência, em que medida a desproteção ambiental, que afeta o açude de Coremas e todo o seu bioma impede o desenvolvimento, em sua acepção mais ampla, das comunidades locais, tornando-se um problema na gestão dos recursos hídricos no Brasil?

Inúmeros problemas vêm surgindo em decorrência do baixo volume de água em Coremas, como interrupção do abastecimento de água por vários dias, em muitas cidades, 
mortalidade dos peixes desse açude e de seus afluentes, impossibilidade de utilizar água para o cultivo e a pecuária, prejudicando a agricultura e a pecuária familiar de subsistência, e aumento da proliferação de doenças relacionadas com a higiene e com a nutrição.

Tais consequências transcendem a atual geração, alcançando, portanto, as futuras. Destaca-se que o direito ao meio ambiente sadio é constitucionalmente protegido não apenas para a presente geração como para as vindouras, de modo que a atual não pode prejudicar as outras, ao esgotar os recursos naturais, como a água do Açude de Coremas.

Desse modo, objetiva-se, em linhas gerais, compreender o papel do Estado na consecução do desenvolvimento, a presente crise hídrica pela qual passam as cidades abastecidas pelo açude de Coremas e ainda apontar algumas medidas de combate à desertificação desse importante reservatório hídrico da região do Vale do Piancó-Paraíba.

A metodologia de abordagem utilizada para este estudo será a dedutiva. No tocante ao procedimento, o método empregado será o explicativo, como técnica de pesquisa, a bibliográfico-documental, a fim de estudar os ditames legais e os posicionamentos doutrinários inerentes ao tema e relacioná-los com os dados do volume hídrico do Açude Coremas/PB.

\section{O ESTADO BRASILEIRO COMO PROMOTOR DO DESENVOLVIMENTO}

A Carta Constitucional brasileira de 1988 trouxe, em seu cerne, inúmeras orientações quanto à promoção dos direitos humanos fundamentais, não se restringindo apenas à instituição da república ou a limitar o poder estatal. Para além disso, contém um projeto de desenvolvimento econômico, social, político e cultural voltado a realização da dignidade humana.

A preferência brasileira pela visão global de desenvolvimento, bem como a relevância do papel estatal nessa empreitada, fica evidente através da leitura do artigo $3^{\circ}$ da Constituição Federal de 1988. Os compromissos cunhados no aludido dispositivo transmitem uma clara mensagem de que o desenvolvimento econômico somente será viável se, ao lado do incremento financeiro, forem observadas também a construção de uma sociedade livre, justa e solidária, a erradicação da pobreza e da marginalização, a redução das desigualdades sociais e regionais e a promoção do bem-estar geral (BRASIL, 2019). 
Para Rister (2007), este pensamento é evidenciado desde o preâmbulo. Além disso, os fins do Estado ultrapassam o âmbito político, para permear o âmbito jurídico de discussão, espraiando um conjunto de compromissos constitucionais que devem vincular a atuação do poder público nas mais variadas esferas. Ferreira Filho (apud CANOTILHO, 2008), assevera que a Carta Magna brasileira deve se configurar como um grande programa de transformações políticas, econômicas e sociais.

Ainda sobre a temática, Feitosa (2012) aduz que:

O Capítulo da ordem econômica (artigo 170 e seguintes), no conjunto de seus princípios e fundamentos, trata a matéria econômica com vistas à realização das metas de transformação social e de maximização do interesse nacional, mesclando valores de direito público e de direito privado, ética e direitos humanos (FEITOSA, 2012, p. 28).

Esse conjunto de compromissos com a transformação socioeconômica nada mais é do que o pacto constitucional pelo desenvolvimento do Estado Brasileiro. A esse respeito, Grau (2010), arrazoa que o processo de desenvolvimento deve transporta a estrutura social para um outra, que eleve tanto o nível econômico como o cultural-intelectual comunitário e, com isso, o desenvolvimento não deve ser entendido apenas como crescimento.

Desse modo, indubitavelmente a CRFB/88 evidencia a importância do papel do Estado brasileiro na promoção do desenvolvimento, não somente no viés puramente econômico, mas em suas múltiplas concepções, responsáveis, por exemplo, pela promoção do bem-estar social. É nesse sentido que Araújo (2017, p. 568) assevera:

Essa transformação social é indispensável para a continuidade e concretização das teorias democráticas, cujo fundamento maior é a união das regras do Estado de Bem-Estar Social no afã de se efetivar a justiça social. Nessa esteira, a reflexão atual a respeito da organização do Estado não pode deixar de considerar os fenômenos econômicos (mundialização, globalização) nem muito menos os problemas daí advindos, tais como a ampliação das desigualdades regionais, o recrudescimento dos quadros de pobreza e miséria, a exclusão política, intelectual, cultural e tecnológica.

O agir estatal nessa conjuntura é fundamental, sobretudo diante da falta de convergência espontânea entre os esforços dos agentes econômicos, consubstanciando um requisito indispensável à promoção de justiça social e de desenvolvimento em solo brasileiro. Ademais, as políticas públicas estatais aparecem como instrumentos capitais na organização jurídica do modo de produção econômica (AGUILLAR, 2014). 
É interessante destacar que a atuação estatal na promoção do desenvolvimento econômico reverberará diretamente na concretização do bem-estar social. Sobre isto, pontua Bercovici (2005), in verbis:

O desenvolvimento é condição necessária para a realização do bem-estar social. O Estado é, através do planejamento, o principal promotor do desenvolvimento. [...] Coordenando as decisões pelo planejamento, o Estado deve atuar de forma muito ampla e intensa para modificar as estruturas socioeconômicas, bem como distribuir e descentralizar a renda, integrando, social e politicamente, a totalidade da população (BERCOVICI, 2005, p. 51-52, grifo nosso).

Em inteligência ao raciocínio supra, pode-se afirmar que o desenvolvimento também está associado à liberdade e, por sua vez, à igualdade de oportunidades, superando a distribuição de renda, para abranger características físicas e sociais, como destacam Lannes e Ferreira (2018):

[...] quanto mais o povo é privado das oportunidades sociais (educação e saúde), políticas (liberdade de expressão e eleições livres) e econômicas (participação no comercio e na produção), menor é a sua liberdade individual e, em consequência, mais restritas ficam suas possibilidades de usufruir os benefícios (e as liberdades) que o desenvolvimento pode proporcionar (FERREIRA; LANNES, 2018, p.98, grifo nosso).

A construção de uma compreensão ampla de desenvolvimento passa necessariamente pela maior amplitude dos cidadãos, através das oportunidades sociais que garantem a melhoria das condições de vida e do bem-estar. Nessa linha, afirma Sen (2008):

A extensão da desigualdade real de oportunidades com que as pessoas se defrontam não pode ser prontamente deduzida da magnitude de desigualdade de rendas, pois o que podemos ou não fazer, podemos ou não realizar, não depende somente das nossas rendas, mas também da variedade de características físicas e sociais que afetam nossas vidas e fazem de nós o que somos (SEN, 2008, p. 60).

Mas o que se entende por bem-estar social? A despeito de existirem diversos posicionamentos, parece mais contundente a visão que apresenta o bem-estar social como um conjunto de ações que possibilitam o indivíduo suprir suas necessidades, conter os problemas e maximiza as oportunidades de vida, conforme apresenta Kerstenetzky (2012).

Ainda, segundo a autora, as necessidades sociais que o Estado de Bem-Estar Social deve satisfazer não se restringem às necessidades materiais, é preciso conter serviços universais de superação de estigmas, para, especialmente de maneira prévia, viabilizar a construção de uma identidade de pessoas, afastando a alienação social, para dar lugar a integração social. 
Com efeito, o Estado brasileiro deve atuar para a superação do subdesenvolvimento, pois dificilmente brotará da espontaneidade do mercado as mudanças estruturais necessárias para alocar o Brasil na esteira o desenvolvimento (FURTADO, 1998). Porém quais políticas desenvolvimentistas adotar?

É sabido que o Estado brasileiro possui um enorme potencial de recursos naturais, entre eles a água, todavia, muitas vezes esta é mal gerenciada, havendo desperdícios e poluição. O controle eficiente e correto da água pode se apresentar como uma política de desenvolvimento, uma vez que tal recurso é a base de toda a vida na Terra, conforme se demonstrará a seguir.

\section{3 ÁGUA COMO ELEMENTO FUNDAMENTAL À VIDA}

A água apresenta-se como o elemento mais importante existente na natureza, pois é dela que brota vida para todos os organismos no Planeta Terra. O ser humano, por exemplo, possui, em sua composição, pouco mais de $70 \%$ de água, o que o impede de viver, desde a sua concepção até a morte, sem esse bem precioso.

Ao longo do tempo, a água foi utilizada em abundância, pois se acreditava que era um recurso inesgotável, contudo a humanidade percebeu que esse elemento é finito, caso não lhe seja dado o uso correto (PIMMEL, 2012).

Há muita água na Terra, principalmente, na forma líquida, que corresponde a aproximadamente $97,72 \%$ de todas as formas possíveis (sólida, líquida ou de vapor), porém, dessa quantia, apenas 0,72\% é doce, sendo a restante salgada (FIORILLO, 2013). Ainda, desse percentual de água doce, $75 \%$ estão congelados nas calotas polares, $10 \%$ estão confinados nos aquíferos e, assim, apenas $15 \%$ dos recursos hídricos doces estão disponíveis no estado líquido (TUNDISI, 2003).

A água, portanto, é um recurso extremamente reduzido. O suprimento de água doce de boa qualidade é essencial para o desenvolvimento econômico, para a qualidade de vida das populações humanas e para a sustentabilidade dos ciclos no planeta.

Repise-se que água é sinônimo de vida e que sem ela não é possível o desenvolvimento ou evolução de qualquer tipo de sociedade. Nesse sentido, são os ensinamentos de Tundisi (apud MONTIPÓ, 2012, p.114, grifo nosso):

Onde não há água não há vida. As grandes civilizações do passado e do presente sempre dependeram de água doce para a sua sobrevivência e 
desenvolvimento cultural e econômico. A água doce é, portanto, essencial à sustentação da vida, e suporta também as atividades econômicas e o desenvolvimento.

A água é imprescindível para o crescimento das civilizações, contudo, na busca desenfreada pelo desenvolvimento, os homens degradam o meio ambiente, caminhando no sentido do prejuízo social e ecológico e ampliando, consequentemente, as injustiças sociais (MONTIPIÓ, 2012). A percepção acerca da água deve ser compreendida numa sistemática de sustentabilidade $^{3}$ e preservação que garanta o seu usufruto, em face das intenções econômicas, mas principalmente como garantia de vida saldável para gerações vindouras. Deste modo, ainda que dependa de água para sobreviver e para desenvolver a economia, os humanos não têm cautela ao utilizar esse importante recurso natural e são responsáveis por poluí-lo, através do despejo de resíduos líquidos e sólidos em açudes, rios e nascentes, contribuindo para a constante destruição do meio ambiente e para a perda quantitativa e qualitativa de boa parte da água doce.

\subsection{RECURSOS HÍDRICOS E O DESAFIO NA GESTÃO DOS DAS ÁGUAS NO BRASIL}

No Brasil, a preocupação com a água começou por volta da década de 1930, com o Decreto 24.643/1934 - Código de Águas, que tratava a água como um bem predominantemente privado, pertencente ao direito de vizinhança. Com a Lei dos Recursos Hídricos (Lei $\mathrm{n}^{\circ}$ 9.433/97), a água passou a ser reconhecida como bem de domínio público e recurso natural limitado, dotado de valor econômico, conforme observado no art. $1^{\circ}$ dessa lei, o qual trouxe os fundamentos da Política Nacional de Recursos Hídricos, veja-se:

Art. $1^{\circ}$ A Política Nacional de Recursos Hídricos baseia-se nos seguintes fundamentos:

I - a água é um bem de domínio público;

II - a água é um recurso natural limitado, dotado de valor econômico;

III - em situações de escassez, o uso prioritário dos recursos hídricos é o consumo humano e a dessedentação de animais;

IV - a gestão dos recursos hídricos deve sempre proporcionar o uso múltiplo das águas;

\footnotetext{
${ }^{3}$ Nesse sentido, Araújo e Arruda (2011, p. 237) apontam que: “O desenvolvimento sustentável [é] baseado em princípios da livre colaboração entre os povos, entre as trocas de informações, de culturas, de conhecimentos tradicionais e científicos, o uso da tecnologia, e da visão de um mundo justo, equilibrado, em busca de um ideal comum de proteção ambiental e consciência ecológica visam a produção racional e condizente com padrões seguros de mínimo existencial". Mencionada compreensão se coaduna com a ideia de desenvolvimento multifacetado que aqui se apresenta, uma vez que reconhece a importância do crescimento econômico como medida para a solução dos problemas sociais, na mesma medida em que entende que apenas com a superação da pobreza e das desigualdades será possível estabelecer um nível mínimo de bem-estar.
} 
V - a bacia hidrográfica é a unidade territorial para implementação da Política Nacional de Recursos Hídricos e atuação do Sistema Nacional de Gerenciamento de Recursos Hídricos;

VI - a gestão dos recursos hídricos deve ser descentralizada e contar com a participação do Poder Público, dos usuários e das comunidades (BRASIL, 1997, grifo nosso).

Pode-se dizer que foi um grande avanço na gestão da água, uma vez que ela passou a ser descentralizada, constituindo um dever de todos, Poder Público, usuários e sociedade, contribuir para o uso racional.

Segundo Viegas (2008), através da legislação infraconstitucional, ocorreu a publicização integral da propriedade da água, cristalizando, portanto, o que já havia disposto a Constituição Federal de 1988, no inciso III do art. 20 e no inciso I do art. 26, respectivamente, que as águas são bens da União e dos Estados. Ainda, conforme o autor, todo bem público, apesar de integrar o patrimônio do Estado, existe para a satisfação do povo, de modo que o objetivo da titularidade do bem, no caso, da água, seja para assegurar as necessidades da comunidade.

Nesse diapasão, tem-se que a Lei no 9.433/97 já surgiu em consonância com a Lei da Política Nacional do Meio Ambiente - PNMA (Lei ${ }^{\circ}$ 6.938/81) e com a Carta Magna brasileira de 1988, que, além de instituir a água como um bem coletivo, também dispõe que a proteção do meio ambiente é um dever comunitário.

É dizer:

Art. 225. Todos têm direito ao meio ambiente ecologicamente equilibrado, bem de uso comum do povo e essencial à sadia qualidade de vida, impondose ao Poder Público e à coletividade o dever de defendê-lo e preservá-lo para as presentes e futuras gerações (BRASIL, 1988, grifo nosso).

Como se vê, constitucionalmente, a ideia de preservação e promoção do uso equilibrado das águas encontra-se cristalizado, o que deve ainda ser ampliado para todas as esferas da federação. Assim, além das disposições nacionais, a Organização das Nações Unidas (ONU), através da Conferência das Nações Unidas para a Água (1977), da Década Internacional de Abastecimento de Água Potável e Saneamento (1981-1990) e da Agenda 21, por exemplo, elaborou, em linhas gerais, algumas diretrizes, com o fim de proteger a qualidade e o abastecimento dos recursos hídricos e assegurar a água doce para as presentes e para as futuras gerações.

De acordo com Selborne, 
O Relatório Bruntland, Nosso Futuro Comum (Comissão Mundial sobre o Desenvolvimento e o Meio Ambiente, 1987), Cuidando da Terra (Relatório de 1991 da União Conservacionista Mundial, do Programa das Nações Unidas para o Meio Ambiente e do Fundo Mundial para a Natureza) e a Agenda 21 da Conferência das Nações Unidas sobre o Desenvolvimento e o Meio Ambiente (Rio de Janeiro, 1992) marcaram uma mudança importante na forma como pensamos sobre a água e os ecossistemas. Um princípio fundamental que emergiu dessa mudança foi o de que a vida das pessoas e o meio ambiente estão profundamente interligados, e que os processos ecológicos mantêm o planeta capacitado a sustentar a vida, proporcionandonos alimento, ar para respirar, remédios e boa parte do que chamamos de qualidade de vida (SELBORNE, 2001, p. 46).

Igualmente é a preocupação da União Europeia com a gestão das águas, consoante dispôs no "Título XX, O Ambiente", notadamente, no artigo 192º ponto 2, alínea "b", 2º do Tratado sobre o funcionamento da União Europeia, estabeleceu que medidas deveriam ser adotadas a fim de assegurar os recursos hídricos. Assim dispõe o referido artigo:

Art. $192^{\circ}$. [... 2. Em derrogação do processo de decisão previsto no n. ${ }^{\circ} 1 \mathrm{e}$ sem prejuízo do disposto no artigo $114^{\circ}$, o Conselho, deliberando por unanimidade, de acordo com um processo legislativo especial e após consulta ao Parlamento Europeu, ao Comité Económico e Social e ao Comité das Regiões, adotará: [...] b) As medidas que afetem: - o ordenamento do território, - a gestão quantitativa dos recursos hídricos ou que digam respeito, direta ou indiretamente, à disponibilidade desses recursos (grifo nosso).

Não obstante as mencionadas disposições legais, as ações da ONU, as considerações de Selborne e o exemplo da União Europeia, pode-se dizer que os recursos hídricos, no Brasil, nunca foram administrados pensando no futuro, visando ao real desenvolvimento e de maneira a evitar a seca nos reservatórios do país.

O Brasil tem o privilégio de possuir uma das maiores bacias hidrográfica do mundo, além de grandes reservas de águas subterrâneas, como a Bacia Amazônica, que possui mais de sete milhões de quilômetros quadrados, e o Aquífero Guarani, que tem reserva estimada em 112 bilhões de metros cúbicos (PIMMEL, 2012).

Contudo, não se pode esquecer que este recurso é esgotável, inclusive, há muitas regiões do país que a falta de água já é uma realidade diária, impactando diretamente na saúde, na qualidade de vida e no desenvolvimento econômico e social da região. Em regiões como o Nordeste, onde o problema da seca é pendular e castiga a população, o desafio na gestão das águas é ainda maior, exigindo do poder público soluções que compatibilizem o desenvolvimento regional com a preservação do meio ambiente. 


\section{AÇUDE DE COREMAS: DESERTIFICAÇÃO, ESGOTAMENTO E MÁ GESTÃo DOS RECURSOS HÍDRICOS NO ALTO-SERTÃO PARAIBANO}

A má gestão dos recursos hídricos é perceptível em todo o Estado Brasileiro e, como resultado dessa operação irracional, vários reservatórios de água se encontram em situação crítica, estando os piores casos localizados na região nordeste do país, cujo clima, por si só, já não é tão favorável ao acumulo de água.

No Estado da Paraíba, o maior reservatório encontra-se com uma capacidade baixa. Em razão disso, muitas das cidades abastecidas pelo Açude de Coremas passam mais de 15 dias para receberem água, já em outras, é necessário que a população compre água de abastecedores privados (os famosos carros pipas), sem os quais, não haverá água sequer para beber, tampouco para fazer a higiene pessoal.

A situação do reservatório do aquífero de Coremas já vem mostrando sinais de alerta, uma vez que, desde meados de 2009, após a sua última cheia, é possível ver a sua constante diminuição, não se atingindo os níveis anteriores.

Segundo o monitoramento do volume dos açudes realizado pela AESA, tomando como ponto de partida o mês de junho de 2012, o volume em Coremas caiu de 60,4\% para 42,71\% em 2013; em 2014, o volume foi para 37,38\%; já em 2015, contabilizou 19,28\%; em junho de 2016, chegou a 7,1\%.

A partir de 2017 houve um pequeno crescimento, registrando um volume de 8,82\%; em 2018 subiu para 18,85\%; e, em junho de 2019, fora registrado o volume de água em $16,81 \%$, todavia, o volume não chegou a superar os $20 \%$ da capacidade do reservatório. Observe-se:

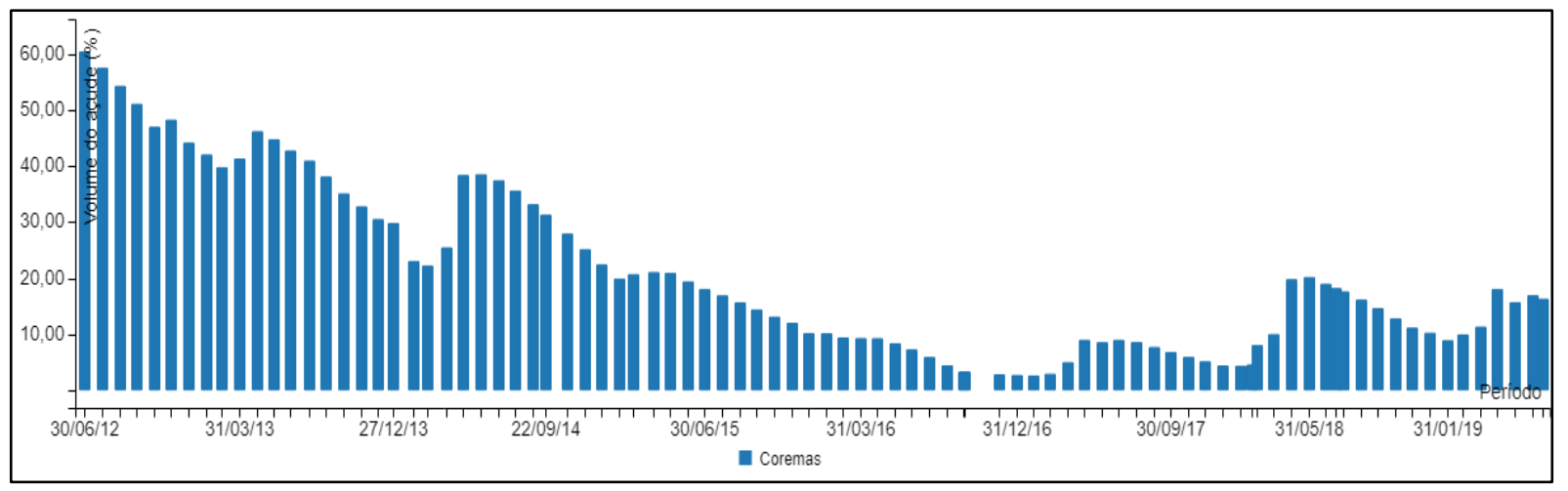

Gráfico I - Percentual do volume de água no Açude de Coremas, segundo a AESA/PB.

Ainda, como é possível observar na Tabela I (Histórico do volume de água do Açude de Coremas) abaixo, nos meses de estiagem que são, principalmente, setembro, outubro, 
novembro, o volume de águas fica ainda menor e, por conseguinte, mais preocupante, dada a essencialidade da água para o ser humano.

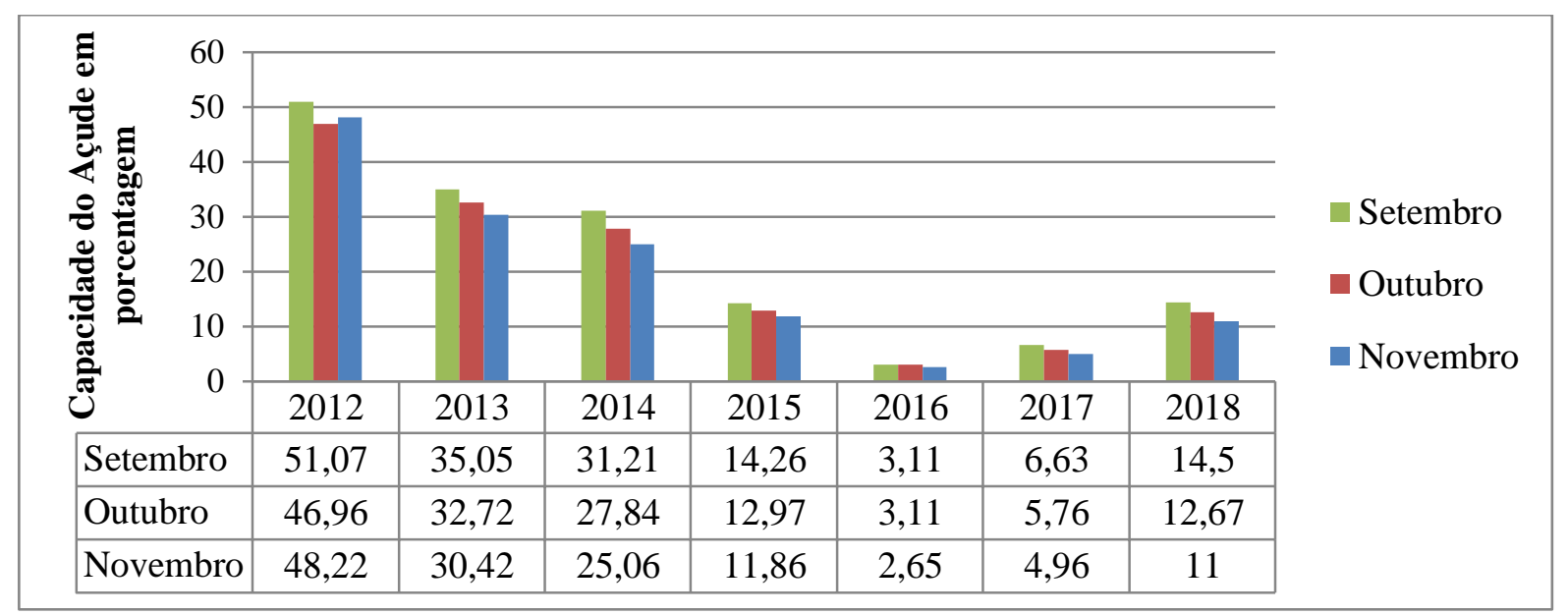

Tabela I - Histórico do volume de água do Açude de Coremas

Apesar de ter sido previsível a atual crise hídrica da região do Vale do Piancó, em oito anos, houve uma redução média de mais de $75 \%$ da reserva aquífera de Coremas, em relação a junho de 2012. Considerando o melhor momento do açude, qual seja, em junho de 2012, quando o volume de água atingiu 60,4\% e o pior, que foi em janeiro de 2017, em que a capacidade ficou em $2,43 \%$, tem-se que o volume de águas reduziu quase $96 \%$.

Essa redução é preocupante, pois demonstra o esgotamento desse bem vital e essencial para promoção do desenvolvimento de uma região que sofre sistematicamente com a seca e que tem os seus níveis de bem-estar severamente comprometidos pela estiagem. Conforme asseveram Araújo e Arruda (2010, p. 297), o processo de desertificação está intimamente ligado aos problemas sociais que afligem o povo nordestino:

Conforme o processo de desertificação avança mais pessoas são afetadas, mais agricultores perdem suas terras férteis, mais animais morrem e a natureza é agredida. No processo de desertificação as cidades do interior nordestino onde se concentra o processo repelem seus habitantes da zona rural para as médias e grandes cidades.

O problema da seca se coloca como uma barreira a promoção do desenvolvimento, uma vez que afeta o acesso à água, o que acaba por depender muito mais da natureza, do que propriamente de um conjunto sistemático de políticas púbicas, historicamente escassas na região. Ao tratar da dependência clara e exclusivamente da natureza, tem-se que, no corrente ano de 2019, em virtude das chuvas, o volume hídrico do reservatório de Coremas teve um pequeno crescimento, entretanto a sua capacidade não superou os $20 \%$, o que não é, nem de longe, suficiente para resolver os problemas da população que depende desta água. 
Há de se alertar que, a partir do mês de agosto começa o período de estiagem, o que leva a crer que os índices do reservatório ficarão semelhantes aos registrados nos anos anteriores. Veja-se a Tabela II (Volume de água do Açude de Coremas no ano de 2019):

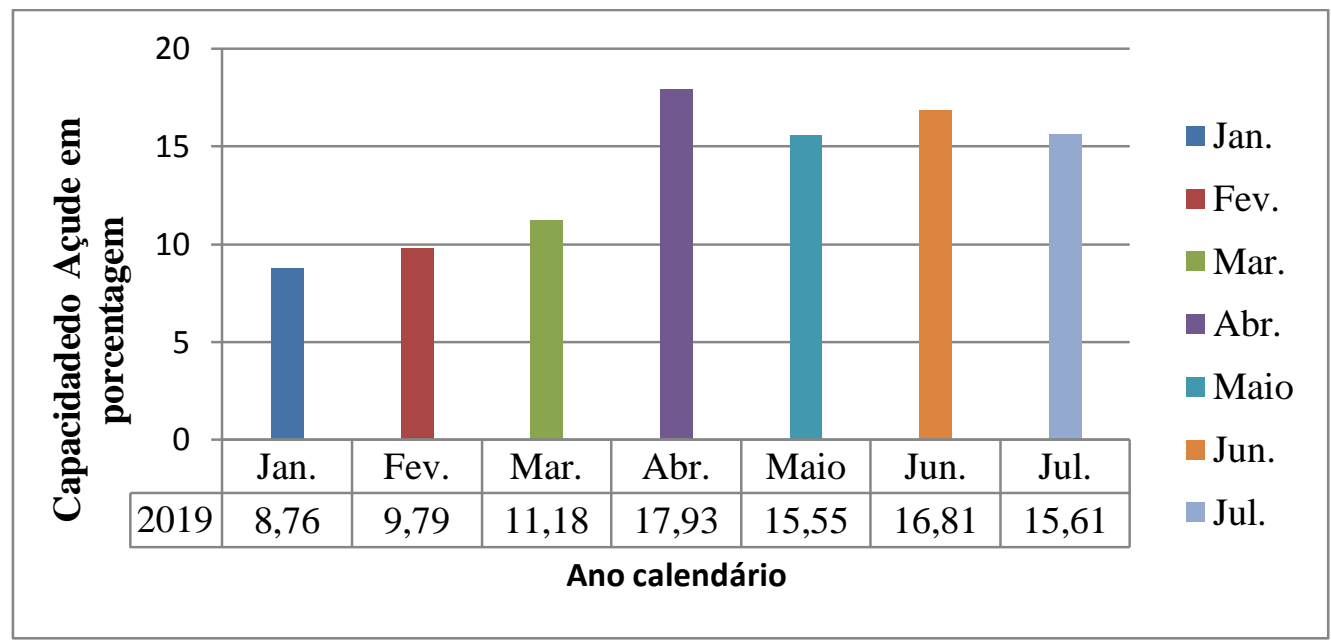

Tabela II - Volume de água do Açude de Coremas no ano de 2019

Nesse contexto, como apontado no ponto 2 deste artigo, lembra-se que a Constituição da República Federativa do Brasil de 1988 optou por uma preferência global de desenvolvimento, para isto, atribuiu ao Estado um papel fundamental na concretização do projeto desenvolvimentista, o qual é clarificado, sobremodo, pelo artigo $3^{\circ}$, do Texto Maior, as quais devem ser efetivadas pelo poder público em suas várias esferas. Nesse sentido, Araújo e Arruda (2010, p. 299) asseveram que:

O combate aos efeitos das secas, a amenização dos rigores climáticos, a amenização dos tempos de estiagem prolongada e o combate eficiente contra a desertificação passa por determinação político-administrativa. Sem a ação do Estado, da iniciativa privada, do envolvimento científico e tecnológico aliado ao povo o problema certamente não terá todas as suas causas e efeitos devidamente combatidos.

O fato de o homem esquecer de integralizar ao processo de desenvolvimento a proteção ao meio ambiente ocasionou a crise ambiental, cujos impactos são globais e facilmente percebidos, não se limitando a um ou outro país ou região.

Sobre o assunto, Leff (2009) arrazoa:

A crise ambiental - de energia, recursos naturais e alimentos - colocou em evidência os desajustes entre a conformação ecossistêmica do planeta e a apropriação capitalista da natureza. $O$ ambiente e os recursos naturais constituem a base material para qualquer forma de desenvolvimento econômico. Desta forma, a "inconsciência ambiental" da teoria e da prática dos paradigmas econômicos prevalecentes aparece como um efeito 
ideológico do processo histórico de exploração do trabalho e da natureza (LEFF, 2009, p. 205, grifo nosso).

Destarte, o desenvolvimento deve ocorrer pari passu com a proteção do meio ambiente, que, no presente caso, clama por uma boa administração dos recursos hídricos, a fim de garantir um cenário próspero não só para as regiões abastecidas pelo açude, mas para todo o estado da Paraíba e para parte do estado do Rio Grande do Norte.

Para Selborne (2001), a administração da água está fortemente ligada à justiça ambiental, baseando-se em conceitos fundamentais, como a equidade, a justiça e o acesso dessa geração e das vindouras.

Em igual linha de raciocino, Montipó (2012) afirma:

A justiça ambiental é fator preponderante no sentido de dar aporte aqueles que mais sofrem com as questões ambientais, como a crise dos recursos hídricos, os desastres naturais e o aquecimento global, visto que todos são atingidos, mas não da mesma maneira. Para tal, faz-se impreterível um Estado devidamente organizado e atento aos problemas que assolam a humanidade, tratando a todos com igualdade e com valores de solidariedade. (MONTIPÓ, 2012, p.116).

Caso não haja uma modificação no gerenciamento das águas do açude Coremas, as previsões revelam um quadro ainda mais preocupante, tendo em vista que os problemas de saúde, como a diarreia, a desnutrição e as verminoses, só aumentarão, bem como a escassez dos alimentos, a mortalidade da fauna e da flora e a elevação da temperatura. Assim sendo, haverá grande injustiça ambiental, social e econômica com a população da região.

\subsection{ESTRATÉGIAS PARA EVITAR A DESERTIFICAÇÃO DO AÇUDE DE COREMAS E DAS REGIÕES ABRANGIDAS}

O Poder Público, os usuários e a sociedade não podem olvidar da responsabilidade de gerir corretamente as águas do Açude de Coremas, em razão da preciosidade e da essencialidade desse recurso natural para todos os organismos vivos da presente e das futuras gerações. Desse modo, sem a conscientização e sem a mudança na forma de utilização da água, haverá desertificação do açude Coremas, e esgotá-lo é dizer não à vida.

A racionalidade ambiental é extremamente relevante pelo fato de agregar questões ambientais às problemáticas sociais, guiando os estudos para o campo estratégico do poder e da ação política e fornecendo medidas para o enfrentamento da crise da água. Entre elas, podem-se destacar as práticas que envolvem a gestão adequada dos recursos, o fornecimento 
de água potável, o racionamento dos recursos públicos e a instrução para o tratamento de esgoto, que evita doenças e proporciona uma melhor qualidade de vida à população (VIEGAS, 2008).

Nesse diapasão, é fundamental que a população seja orientada sobre a necessidade de ter um meio ambiente sadio e alertada acerca dos eventuais prejuízos da degradação ambiental e do esgotamento dos recursos naturais, no caso em tela, da água doce, sempre tendo como objetivo a sustentabilidade do seu uso.

Para Leff (2009, p. 217):

As estratégias do ecodesenvolvimento circunscrevem-se a um campo de ações práticas para refuncionalizar a racionalidade econômica, incorporando uma "dimensão ambiental" às políticas do desenvolvimento. Esta visão sistêmica e pragmática desconhece o potencial crítico do ambiente e dos conflitos sociais pela apropriação da natureza. Estes se evaporam na transparência das práticas da planificação ambiental. Contudo, o conceito de ambiente tem um sentido estratégico no processo político de supressão das "externalidades do desenvolvimento" - a exploração econômica da natureza, a degradação ambiental, a desigual distribuição social dos custos ecológicos e a marginalização social - as quais persistem, apesar da ecologização dos processos produtivos e da capitalização da natureza.

Contextualizando a adoção de estratégias para preservação dos recursos hídricos no

Brasil, Tundisi (2014) assevera que no plano gerencial, entre outras, deve ser uma prioridade:

Proteger e recuperar mananciais para aumentar a produção de água potável, preservar a qualidade da água, e diminuir os custos de tratamento. Proteger regiões de aquíferos. Investir em novas tecnologias para tratamento de água, ampliando a capacidade e a qualidade do tratamento, reduzindo custos e aplicando técnicas de reuso de água (TUNDISI, 2014, p. 59).

Outro importante mecanismo para evitar a escassez tanto qualitativa como quantitativa é a cobrança pela utilização da água. Tal instrumento encontra-se previsto na Lei dos Recursos Hídricos (Lei n ${ }^{\circ}$ 9.433/97), conforme se observa da leitura do seu art. 19, que diz:

Art. 19. A cobrança pelo uso de recursos hídricos objetiva:

I - reconhecer a água como bem econômico e dar ao usuário uma indicação de seu real valor;

II - incentivar a racionalização do uso da água;

III - obter recursos financeiros para o financiamento dos programas e intervenções contemplados nos planos de recursos hídricos.

Não há dúvidas de que a elevação da tarifa de uso da água pode ser um importante meio, para indicar o valor econômico desse bem, para induzir comportamentos e para angariar fundos para o investimento em programas destinados à correta gestão dos recursos hídricos, 
porém é preciso que a precificação da água não seja mais um fato de injustiça ambiental, impedindo as populações carentes de terem acesso à água, em detrimento das pessoas com um poder aquisitivo suficiente para o consumo, ou pior, para ter o "direito de degradar" o meio ambiente. Não se pode esquecer que:

É no semi-árido que se concentram também mais de $2 / 3$ dos pobres rurais brasileiros e, segundo estimativa do IPEA, mais da metade da população vítima da fome e da má nutrição. A desertificação é ao mesmo tempo causa e efeito da pobreza. A pobreza obriga quem vive da terra a sobre-explorar esta terra para obter alimentos, energia, habitação e uma fonte de renda (DUQUE, 2006, p. 78).

Assim, todas as questões "sociais" que envolvem o uso da água devem ser levadas em consideração. Com o avanço tecnológico, tem-se a biotecnologia, que, apesar de se orientar majoritariamente para o monocultivo de espécies mais fortes frente aos ataques de pragas, às secas e à salinidade do solo, também pode associar-se a outras formas de desenvolvimento, possibilitando o manejo múltiplo e integrado de recursos, a conservação dos solos e a reciclagem de resíduos (LEFF, 2009), que, por sua vez, corroboram para o racionamento dos recursos hídricos.

Segundo Viegas (2008), é superficial pensar que a ausência de água é uma mera falta dela, na verdade, as consequências são a falta de comida, de produção, de saúde, de dinheiro, de estima e de cidadania. Em consonância ao apresentando no início deste trabalho, pode-se afirmar que a falta de água afeta diretamente o bem-estar social da pessoa humana, como a liberdade e a igualdade de oportunidades.

No tocante ao Açude de Coremas, o atual volume de água reforça a necessidade da adoção de medidas urgentes, além da união de forças, de modo que não recaiam apenas sobre o Poder Público o dever de proteger esse reservatório, bem como a culpa por ter transformado a região do Vale do Piancó em deserto, uma vez que, como já apontado, a CRFB/88 assevera que é dever de todos zelar pelo meio ambiente. É nesse sentido que a educação ambiental, como instrumento de disseminação de diretrizes e práticas econômicas e também de conscientização social, se coloca como elemento de irrefutável importância na consolidação de um projeto de preservação da água (ARAÚJO; ARRUDA, 2010, p. 300).

Nesse alamiré, de imediato, é preciso que a gestão das águas de Coremas ocorra de maneira conjunta entre a população, os usuários e o Poder Público e que a utilização dessas águas seja prioritariamente para o consumo humano, após o devido tratamento, a fim de combater, todo e qualquer desperdício de água, tanto em quantidade e como em qualidade. 
Lembra-se que o Estado deve promover o desenvolvimento econômico, assim, é dever do Poder Público controlar os recursos hídricos através de políticas públicas eficazes, como o investimento de recursos na implantação da rede de coleta e de tratamento de esgotos, a fiscalização e a modernização do sistema de fornecimento de água, a preservação das nascentes, a realização de cursos de conscientização e a capacitação para a reutilização da água, sendo exemplo de usuário racional dos recursos hídricos.

Incumbirá à população a fiscalização, a mobilização em prol do uso correto e a não poluição da natureza, devendo utilizar o bem racionalmente, para evitar a degradação desenfreada do meio ambiental e a educação ambiental tem um papel primordial:

Educação Ambiental é então o meio profícuo para formar uma sociedade politizada e com objetivos claros e concisos capazes de induzir mecanismos ensejadores de políticas setoriais voltadas para o meio ambiente. Quanto mais esclarecida a sociedade nordestina sobre os efeitos da desertificação, modos de controle e mitigação dos seus efeitos melhor será para o sertanejo conviver com o clima semi-árido (ARAÚJO; ARRUDA, 2010, p. 301).

Evidentemente, cabe à natureza e ao clima, através das chuvas, a elevação dos níveis de água do aquífero de Coremas, é o que o povo nordestino espera. Todavia, é imperioso que uma nova cultura baseada na gestão responsável, por parte do poder público, e na educação ambiental se coloque como fundamento para o manejo das águas, principalmente nessa região tão marcada pela seca.

\section{CONSIDERAÇÕES FINAIS}

O Estado brasileiro é parte fundamental na promoção do desenvolvimento econômico, não é por acaso que a Constituição Federal de 1988, desde o preâmbulo, estabelece um projeto político desenvolvimentista, almejando à liberdade, à promoção de justiça social, à redução das desigualdades sociais e entre outros objetivos.

Outrossim, foi possível compreender a essencialidade da água para a vida de todos os seres do Planeta Terra, notadamente, para o ser humano. Por muito tempo, a água foi considerada um recurso natural inesgotável, contudo se descobriu que, se não for utilizada corretamente, ela será finita.

Apesar de conhecer a importância e a finitude da água, os seres humanos ainda continuam a utilizá-la de modo errôneo, o que traz consequências funestas tanto para a 
presente como para as futuras gerações. No caso do povo brasileiro, principalmente, quem vive nas regiões abastecidas pelo Açude de Coremas, os impactos da escassez já são atuais.

A ingerência e a falta de responsabilidade do Poder Público e da sociedade com o reservatório de Coremas é extremamente danosa. Em oito anos, o açude teve uma redução média de mais de $75 \%$ do volume de água, por conseguinte, famílias passam mais de 15 dias sem ter acesso à água, aumentando o número de doenças, a mortalidade da fauna e da flora e transformando a região em deserto.

É preciso desenvolver a região do Sertão e garantir ao povo um bem-estar social de superação, como assentado na própria Constituição brasileira, porém o desenvolvimento deve acontecer de maneira sustentável, para que os direitos e as garantias fundamentais ao meio ambiente sadio não sejam dilacerados. Para tal, é necessário um conjunto de ações positivas, fundadas principalmente na educação ambiental, as quais devem ser compartilhadas, de forma solidária, entre os entes federativos e a sociedade.

Quanto ao Açude de Coremas, são necessárias medidas urgentes, as quais devem congregar uma gestão correta e eficiente daquele reservatório, a não poluição do meio ambiente e uma mudança de comportamento por parte da sociedade. Em ultima ratio, a implementação de uma gestão coletiva dos recursos hídricos, cabendo à população, aos usuários e ao Poder Público atuarem em prol da correta utilização das águas de Coremas, fiscalizando-se mutuamente, a fim de evitar a desertificação.

\section{REFERÊNCIAS}

AGÊNCIA EXECUTIVA DE GESTÃO DE ÁGUAS DO ESTADO DA PARAÍBA. Monitoramento. Últimos volumes informados dos açudes. Disponível em: <http://www.aesa.pb.gov.br/aesa-website/monitoramento/volume-acude/?id_acude=5261>. Acesso em: 31 jul. 2019.

. Monitoramento. Evolução diária do volume dos açudes: 07/2019. Disponível em: < http://www.aesa.pb.gov.br/aesa-website/monitoramento/volume-diario/?tipo=atual $>$. Acesso em: 31 jul. 2019.

AGUILLAR, Fernando Herren. Direito econômico: do direito nacional ao direito supranacional. 4. ed. São Paulo: Atlas, 2014.

ARAÚJO, Jailton Macena de. Cidadania, desenvolvimento e dignidade humana: uma releitura da esfera pública arendtiana à luz da solidariedade. Pensar, Fortaleza, v. 22, n. 2, p. 567-580, maio/ago. 2017. 
ARAÚJO, Jailton Macena de; ARRUDA, D. B. Desenvolvimento sustentável: políticas públicas e educação ambiental no combate à desertificação no Nordeste. Veredas do Direito, Belo Horizonte, v. 7, p. 289-310, 2011.

ARAÚJO, Jailton Macena de; ARRUDA, D. B. Práticas de Sustentabilidade no Semiárido Nordestino: direito ao desenvolvimento econômico-sustentável. Veredas do Direito, Belo Horizonte, v. 8, p. 235-260, 2011.

BERCOVICCI, G. Constituição econômica e desenvolvimento: uma leitura a partir da Constituição de 1988. São Paulo: Malheiros, 2005.

BRASIL. Constituição da República Federativa do Brasil de 1988. Disponível em: < http://www.planalto.gov.br/ccivil_03/Constituicao/ConstituicaoCompilado.htm>. Acesso em: 20 jul. 2019.

BRASIL. Lei da Política Nacional do Meio Ambiente. Disponível em: < http://www.planalto.gov.br/ccivil_03/Leis/L6938.htm >. Acesso em: 27 jul. 2019.

BRASIL. Lei da Política Nacional dos Recursos Hídricos. Disponível em: < http://www.planalto.gov.br/ccivil_03/leis/L9433.htm>. Acesso em: 23 jul. 2019.

CANOTILHO, J. J. Gomes. "Brancosos" e interconstitucionalidade: itinerários dos discursos sobre a historicidade constitucional. 2.ed. Coimbra: Almedina, 2008.

DUQUE, Ghislaine. Agricultura familiar em regiões com risco de desertificação: o caso do Brasil semi-árido. In: MOREIRA, Emilia (Org.). Agricultura familiar e desertificação. João Pessoa, Editora universitária/UFPB, 2006. p.77-90.

FEITOSA, Maria Luiza Pereira de Alencar Mayer. Direito econômico da energia e direito econômico do desenvolvimento. Superando a Visão Tradicional. In: FEITOSA, M. L. P. de A. M.; PEREIRA, M. M. F.; (Org.). Direito econômico da energia e do desenvolvimento: ensaios interdisciplinares. São Paulo: Conceito, 2012.

FERREIRA, Fabiana Félix; LANNES, Yuri Nathan da Costa. Análise sobre desenvolvimento econômico. In: Direito, economia e desenvolvimento econômico sustentável [Recurso eletrônico on-line] organização CONPEDI/UNISINOS Coordenadores: Everton das Neves Gonçalves; Gina Vidal Marcilio Pompeu. - Florianópolis: CONPEDI, 2018.

FIORILlO, Celso Antônio Pacheco. Curso de direito ambiental brasileiro. 14a ed. rev., ampl. e atual. em face da Rio+20 e do novo "código" florestal. São Paulo: Saraiva, 2013.

FURTADO. Celso. O capitalismo global. São Paulo: Paz e Terra, 1998.

GRAU, Eros Roberto. A ordem econômica na Constituição de 1988. Interpretação e crítica. 14. ed. revista e atualizada. São Paulo: Malheiros, 2010.

KERTENETZKY, C. L. O Estado de Bem-Estar Social na idade da razão: a reinvenção do Estado Social no mundo contemporâneo. Rio de Janeiro: Elsevier, 2012. 
LEFF, Enrique. Ecologia, capital e cultura: a territorialização da racionalidade ambiental. Petrópolis - RJ: Vozes, 2009.

MONTIPÓ, Cristina Dias. Água: direito fundamental e elemento essencial para a dignidade humana. In: Os recursos naturais e o homem: o direito ao meio ambiente ecologicamente equilibrado frente à responsabilidade solidária. BUTZKE, Alindo. E PONTALTI, Sieli. (Org.). Dados eletrônicos, Caxias do Sul, RS: Educs, 2012. p.105-122.

ONU. Conferência das Nações Unidas Sobre Meio Ambiente e Desenvolvimento. Capítulo 18. Disponível em: <https://bit.ly/332pP8f>. Acesso em: 30 jul. 2019.

PIMMEL, Nicole Freiberger. Águas: aspectos ambientais e jurídicos dos recursos hídricos no Brasil. In: Os recursos naturais e o homem: o direito ao meio ambiente ecologicamente equilibrado frente à responsabilidade solidária. BUTZKE, Alindo. E PONTALTI, Sieli. (Org.). Dados eletrônicos, Caxias do Sul, RS: Educs, 2012. p.165-176.

SELBORNE, Lord. A ética do uso da água doce: um levantamento. Brasília: Unesco, 2001. Disponível em: <http://unesdoc.unesco.org/images/0012/001271/127140por.pdf〉. Acesso em: 12 jul. 2019.

SEN, Amartya Kumar. Desigualdade reexaminada. Tradução e apresentação de Ricardo Doninelli Mendes. 2. Ed. Rio de Janeiro: Record, 2008.

RISTER, Carla. Direito ao desenvolvimento - antecedentes, significados e consequências. Rio de Janeiro: Renovar, 2007.

TUNDISI, José Galizia. Recursos hídricos. 2003. Disponível em: <http://www.mobilizadores.org.br/wp-content/uploads/2014/05/recursos-hdricos.pdf>. Acesso em: 26 jul. 2019.

Recursos hídricos no Brasil: problemas, desafios e estratégias para o futuro. José Galizia Tundisi (coordenador). - Rio de Janeiro: Academia Brasileira de Ciências, 2014. Disponível em:

<file:///C:/Users/Din\%C3\%A2mica\%20Inform\%C3\%A1tica/Downloads/RecursosHidricos.pdf>. Acesso em: 31 jul. 19.

UNIÃO EUROPEIA. Tratado sobre o funcionamento da União Europeia. Disponível em: <https://eur-lex.europa.eu/resource.html?uri=cellar:9e8d52e1-2c70-11e6-b49701aa75ed71a1.0019.01/DOC_3\&format=PDF>. Acesso em: 29 jul. 2019.

VIEGAS, Eduardo Coral. Gestão da água e princípios ambientais. Caxias do Sul: Educs, 2008. 